\title{
What controls deuterium excess in global precipitation?
}

\author{
S. Pfahl and H. Sodemann \\ Institute for Atmospheric and Climate Science, ETH Zurich, 8092 Zurich, Switzerland \\ Correspondence to: S. Pfahl (stephan.pfahl@env.ethz.ch) and H. Sodemann (harald.sodemann@env.ethz.ch)
}

Received: 25 July 2013 - Published in Clim. Past Discuss.: 14 August 2013

Revised: 20 February 2014 - Accepted: 2 March 2014 - Published: 22 April 2014

\begin{abstract}
The deuterium excess $(d)$ of precipitation is widely used in the reconstruction of past climatic changes from ice cores. However, its most common interpretation as moisture source temperature cannot directly be inferred from present-day water isotope observations. Here, we use a new empirical relation between $d$ and near-surface relative humidity (RH) together with reanalysis data to globally predict $d$ of surface evaporation from the ocean. The very good quantitative agreement of the predicted hemispherically averaged seasonal cycle with observed $d$ in precipitation indicates that moisture source relative humidity, and not sea surface temperature, is the main driver of $d$ variability on seasonal timescales. Furthermore, we review arguments for an interpretation of long-term palaeoclimatic $d$ changes in terms of moisture source temperature, and we conclude that there remains no sufficient evidence that would justify to neglect the influence of RH on such palaeoclimatic $d$ variations. Hence, we suggest that either the interpretation of $d$ variations in palaeorecords should be adapted to reflect climatic influences on RH during evaporation, in particular atmospheric circulation changes, or new arguments for an interpretation in terms of moisture source temperature will have to be provided based on future research.
\end{abstract}

\section{Introduction}

Stable water isotopes in atmospheric waters are useful tracers of the global hydrological cycle (Dansgaard, 1964; Gat, 1996), and their conservation in proxy archives like ice cores and cave deposits is essential for the reconstruction of past climates (e.g. Jouzel et al., 1982; Dansgaard et al., 1993; Meckler et al., 2012). The deuterium excess, defined as $d=$ $\delta \mathrm{D}-8 \delta^{18} \mathrm{O}$ (where $\delta \mathrm{D}$ and $\delta^{18} \mathrm{O}$ denote the deuterium and oxygen-18 abundance relative to VSMOW - Vienna Standard Mean Ocean Water), is a second-order isotope param- eter that is specifically sensitive to the conditions during the evaporation of water from the (ocean) surface, i.e. the moisture source conditions (Merlivat and Jouzel, 1979; Johnsen et al., 1989; Pfahl and Wernli, 2008). Accordingly, $d$ variations in ice cores and other palaeoclimatic proxy archives are thought to reflect past changes in these source conditions (Jouzel et al., 1982, 2007; Vimeux et al., 1999; Stenni et al., 2001; Masson-Delmotte et al., 2005; Steffensen et al., 2008). Deuterium excess has become a key parameter for studying climate variations, in particular abrupt events recorded in the proxy data (Jouzel et al., 2007; Steffensen et al., 2008). In stable isotope data from Greenland ice cores, rapid (1-3 yr) changes in $d$ have been interpreted as fast reorganisations in the atmospheric circulation associated with changes in the moisture source conditions (Steffensen et al., 2008) and/or locations (Masson-Delmotte et al., 2005). Despite the general sparsity of isotope measurements in evaporating waters a theoretical framework for the interpretation of $d$ exists, which is briefly revisited in the following.

Physically, the deuterium excess reflects the slower movement of the $\mathrm{H}_{2}{ }^{18} \mathrm{O}$ molecule during diffusion, leading to a relative enrichment of the HDO molecules in the less strongly bound phase (e.g. in the gas phase during the evaporation of water). This slower movement can only lead to measurable differences if there is not sufficient time for the two phases to reach isotopic equilibrium. During evaporation, such non-equilibrium conditions are caused by a strong gradient in relative humidity above the water surface, and by winds that advect the evaporate away from the surface before (near-)equilibrium conditions between the two phases can be reached. Following Craig and Gordon (1965) and Merlivat and Jouzel (1979), the isotopic composition $\delta_{\mathrm{E}}^{i}$ of water evaporating from the ocean for the isotopic species $i\left(i={ }^{18} \mathrm{O}, \mathrm{D}\right)$ can be expressed as

$$
1+\delta_{\mathrm{E}}^{i}=\left(1-k_{i}\right) \frac{\alpha_{i}^{-1}-\mathrm{RH}\left(1+\delta_{\mathrm{v}}^{i}\right)}{1-\mathrm{RH}},
$$


where RH is the relative humidity with respect to saturation at the sea surface, $\delta_{\mathrm{v}}^{i}$ is the isotopic composition of the surrounding vapour for species $i, k_{i}$ is the non-equilibrium (diffusive) fractionation factor, and $\alpha_{i}$ is the equilibrium fractionation factor. Sea surface temperature (SST) can influence $d$ via this temperature-dependent equilibrium fractionation factor. The exact formulation of the non-equilibrium fractionation factor as a function of wind speed and potentially temperature is still under discussion (Pfahl and Wernli, 2009; Luz et al., 2009). For analysing variations of $d$ on global scales, Merlivat and Jouzel (1979) introduced a global closure assumption in which the isotopic composition of the surrounding vapour $\delta_{\mathrm{v}}^{i}$ was assumed to be equal to the isotopic composition of global precipitation, which in turn equals the isotopic composition of global evaporation. This allowed to derive a simplified expression for the isotope ratio in water vapour from evaporation:

$\delta_{\mathrm{v}}^{i}=\alpha_{i}^{-1} \frac{1-k_{i}}{1-k_{i} \mathrm{RH}}-1$.

However, as pointed out by Jouzel and Koster (1996), this global closure assumption is typically invalid at local scales. Jouzel and Koster (1996) recommend to use climate model data for $\delta_{\mathrm{v}}^{i}$ in Eq. (1). Nevertheless, climate models are also associated with uncertainties regarding the representation of $d$ (Yoshimura et al., 2008; Risi et al., 2010; Jouzel et al., 2007). Equation (2) can be combined for both isotopes to obtain an expression for $d$ in boundary layer water vapour and thus (implying global closure) in water evaporating from the ocean. Using a simple Rayleigh condensation model, Merlivat and Jouzel (1979) derived a strong dependency of $d$ on RH in the so-called first condensate, the initial precipitation, while the influence of evaporation temperature remained indistinguishable. The later study by Johnsen et al. (1989) directly used the isotopic composition derived from the global closure (Eq. 2) to estimate $d$ locally at an assumed fixed moisture source for Greenland from monthly mean RH and SST values. Thereby simple linear relations were derived between changes in RH and SST and $d$ in the water evaporating from the ocean:

$$
\begin{aligned}
& \frac{\Delta d}{\Delta \mathrm{SST}}=+0.35 \frac{\% \circ d}{\mathrm{KSST}}, \\
& \frac{\Delta d}{\Delta \mathrm{RH}}=-0.43 \frac{\% \circ d}{\% \mathrm{RH}} .
\end{aligned}
$$

RH is a direct factor of influence in Eq. (2), while SST affects the temperature-dependent equilibrium fractionation factors $\alpha_{i}$. According to Eq. (3) $d$ becomes higher with increasing SST and lower with increasing RH, with constants of proportionality of comparable magnitude. Nevertheless, on synoptic timescales, the dependence of $d$ on SST is substantially weaker than on $\mathrm{RH}$, because the variability of RH in percentages typically is much larger than the variability of SST in kelvin. It is common to most studies until now that RH has been considered at relatively long averaging times, compared to the timescale at which evaporation actually takes place, thereby substantially underestimating the variability of RH. From their study with an idealised model, and using monthly mean data for the initialisation, Johnsen et al. (1989) concluded that SST and RH changes could both play a role for $d$ variations observed in a Greenland ice core. Noting that GCM (global circulation model) simulations show only small glacial-to-interglacial changes in mean oceanic $\mathrm{RH}$, it has been proposed that $d$ in Antarctic ice core records can be interpreted as a moisture source SST signal only (Vimeux et al., 1999; Stenni et al., 2001; Uemura et al., 2012), revoking the earlier interpretation as a proxy of moisture source RH (Jouzel et al., 1982). This interpretation as source SST has later been extended also to Greenland ice cores (MassonDelmotte et al., 2005). In recent climate model studies, Lewis et al. (2013) and Risi et al. (2013) investigated the relationship between $d$ and moisture source conditions on different timescales. Lewis et al. (2013) focused on the role of SST, but noted that source RH changes might introduce errors in the $d$-SST relation. Risi et al. (2013) discussed several factors controlling $d$ variations, including moisture source $\mathrm{RH}$ and SST, and emphasised the potential impacts of model uncertainties for the interpretation of these variations.

Recent measurements of $d$ in boundary layer water vapour consistently show that at synoptic timescales (from hours to days), $\mathrm{RH}$ above the ocean surface is highly anti-correlated with $d$ in atmospheric water vapour (Gat et al., 2003; Uemura et al., 2008; Angert et al., 2008; Pfahl and Wernli, 2008; Kurita, 2011). Interestingly, when plotted together against source $\mathrm{RH}$, the $d$ measurements from these studies (Gat et al., 2003; Uemura et al., 2008; Angert et al., 2008; Pfahl and Wernli, 2008) fall on one line (Fig. 1a) although they are from such different geographical regions as the Southern Ocean and the Mediterranean, span a wide range of evaporation conditions, and have been obtained with different approaches (see Sect. 2). This indicates that these $d$ measurements above the ocean are directly related to $d$ of the evaporation flux. Consistently with theoretical considerations (Merlivat and Jouzel, 1979; Craig and Gordon, 1965), these data point to a dominant, universal relationship between $d$ of water evaporating from the ocean and the corresponding near-surface $\mathrm{RH}$. In this study, we apply this relationship in a linear statistical model to globally predict $d$ of the evaporating water. In this way, we avoid the global closure assumption inherent in simple theoretical evaluations (see again Eq. 2) and the uncertainties related to the representation of $d$ in climate models. By using six-hourly RH from ERA-Interim reanalyses (Dee et al., 2011) as predictor, the model explicitly considers the synoptic-scale processes that drive short-term RH variations. On these timescales, $\mathrm{RH}$ and wind speed are the main factors determining oceanic evaporation. The empirical relation applied in our model relates $d$ linearly to a standard meteorological quantity, a linkage that does not directly emerge from theoretical derivations. 

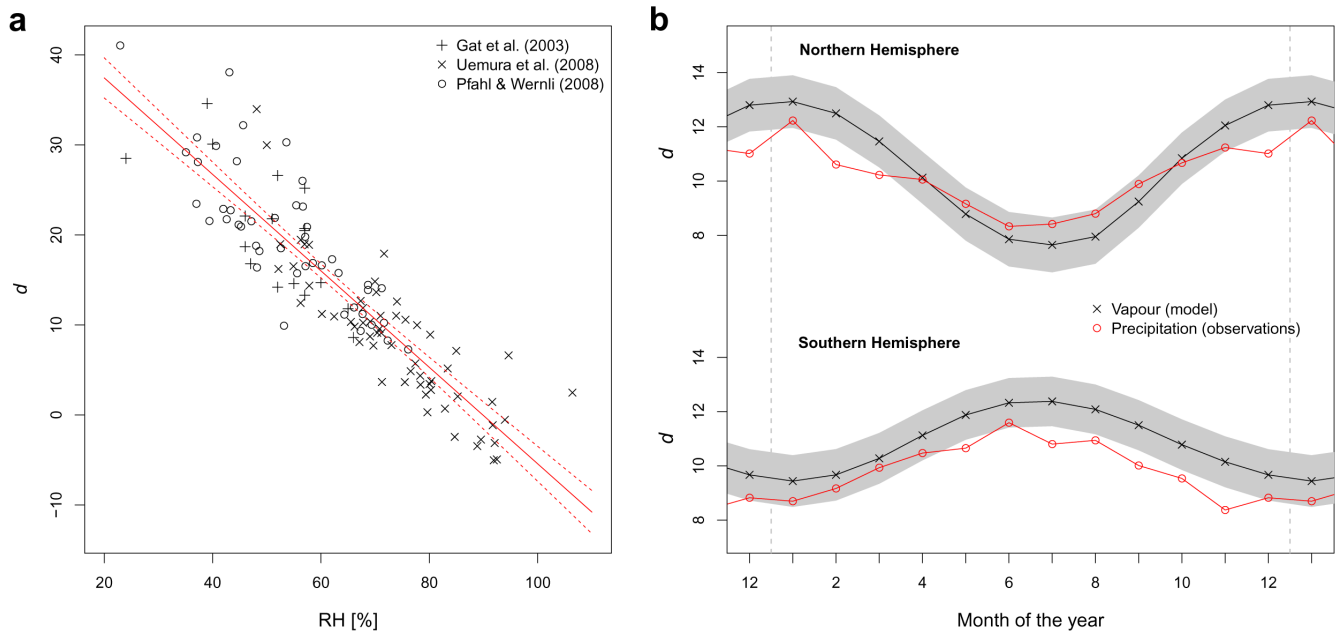

Fig. 1. Deuterium excess $d$ of water vapour and precipitation. (a) Scatter plot of water vapour $d$ from several published data sets (Gat et al., 2003; Uemura et al., 2008; Pfahl and Wernli, 2008) against RH at the oceanic moisture source. The solid red line indicates a linear regression, which is used for the calculation of moisture source $d$ in our statistical model, the dashed lines show the uncertainty of this regression based on a $95 \%$ confidence interval. (b) Seasonal cycle of $d$ in ocean evaporation (black crosses and gray shading), as obtained from the linear regression model based on reanalysis RH, averaged over the Northern and Southern hemispheres. Red circles show hemispherically averaged $d$ of precipitation from GNIP stations.

By comparing the predicted $d$ in evaporation with $d$ measurements in precipitation, we evaluate the relevance of the $d-\mathrm{RH}$ relationship for global precipitation data.

\section{Data and methods}

The statistical model that relates the deuterium excess of water evaporating from the ocean to the near-surface $\mathrm{RH}$ is based on several sets of measurements of $d$ in atmospheric water vapour from the literature (Gat et al., 2003; Uemura et al., 2008; Angert et al., 2008). Gat et al. (2003) performed daily measurements of the isotopic composition of near-surface water vapour on board a ship during a 1 month cruise over the Mediterranean Sea in 1995. The measurements were done at mast and deck height, and the deck data have been used here. Furthermore, measurements have been discarded if precipitation occurred in the vicinity of the ship. Uemura et al. (2008) also measured isotopes in vapour on board a ship, with a measurement frequency of 2-3 times per day. Their cruise took place over the Southern Ocean, from South Africa towards Antarctica and to Australia, in January 2006. Angert et al. (2008) performed isotope measurements in water vapour over $9 \mathrm{yr}$ (sampling about two times a week) at a near-coastal site in Rehovot, Israel. Here only those data have been used for which most of the sampled vapour could be traced back to oceanic evaporation sources with the trajectory method of Pfahl and Wernli (2008). RH is defined with respect to saturation at the sea surface here (as in Eq. 1), i.e. $\mathrm{RH}=q / q_{\mathrm{sat}}(\mathrm{SST})$, where $q$ denotes the specific humidity above the ocean surface, and $q_{\mathrm{sat}}(\mathrm{SST})$ is the saturation humidity at the surface. For ship data from the Mediterranean
(Gat et al., 2003) and the Southern Ocean (Uemura et al., 2008), $q$ and SST have been used as observed in situ. For the station data from Israel (Angert et al., 2008), $q$ and SST in the moisture source regions were reconstructed by means of a trajectory method (see again Pfahl and Wernli, 2008). The very good correlation between measured $d$ in water vapour over the ocean and the locally observed RH shown in Fig. 1a indicates that the $d$ measurements are directly representative for $d$ of the evaporation flux, which is known to be controlled by RH due to physical reasons: during dry conditions, there is a larger humidity gradient between the saturated layer directly at the ocean surface and the sub-saturated atmosphere above, leading to strong non-equilibrium fractionation and thus a high value of $d$ in the evaporating moisture. The association of vapour measurements with evaporation $d$ is further supported by the very good agreement of the in situ data with the reconstructed evaporation conditions of Pfahl and Wernli (2008) (see again Fig. 1a), and the fact that Uemura et al. (2008) have been able to explain most of the variability in their data set by applying this closure assumption. Note, however, that in general vapour and evaporation $d$ at a fixed location can be different (Jouzel and Koster, 1996), and the application of vapour measurements as a proxy for evaporation $d$ may be a potential source of error.

A linear regression has been used to model the relationship between $d$ in ocean evaporation and the near-surface $\mathrm{RH}$, as indicated by the solid red line in Fig. 1a, which corresponds to the equation $d=48.2 \% o-0.54 \% \circ \%^{-1} \mathrm{RH}$. The dashed lines show the $95 \%$ confidence intervals of the linear regression. This regression model has then been applied to predict $d$ of water evaporating from the ocean, 
using RH from meteorological reanalysis data as input. To this end, six-hourly, global fields of specific humidity at $2 \mathrm{~m}$ above the surface (calculated from $2 \mathrm{~m}$ temperature and dew point temperature) and SST for the period 1979-2010 have been obtained from ECMWF (European Centre for Medium-Range Weather Forecasts) ERA-Interim reanalyses (Dee et al., 2011). The data have been interpolated to a $1^{\circ} \times 1^{\circ}$ spatial grid. RH above the ocean surface has then been calculated as described above. In addition, sea ice cover, surface latent heat flux (which is proportional to surface evaporation) and land surface temperature have also been taken from the reanalysis data. The latent heat flux (LHF) is a forecast field, and forecast steps from 6 to 12 and 12 to $18 \mathrm{~h}$ are used, neglecting the first $6 \mathrm{~h}$ because of possible model spinup effects. Near-surface humidity is reasonably well represented in the ERA-Interim data (Simmons et al., 2010; Pfahl and Niedermann, 2011), and using such a reanalysis data set is decisive because of the best possible spatial and temporal coverage it offers. The linear regression model described above has been applied to calculate $d$ of water evaporating from the ocean for each six-hourly time step and each grid point, taking the reanalysis RH as input. The uncertainty of the linear regression is used as an uncertainty estimate for predicted $d$. Note that this estimate does not account for the uncertainties of the individual $d$ and RH measurements and should thus be considered as lower bound of the model uncertainty. Taking errors of individual data points into account is hardly possible, since these depend on various factors such as the related moisture source footprint. Climatological means of $d$ have been obtained at every grid point and for each month and season by averaging the corresponding six-hourly values, weighted with the six-hourly surface latent heat flux. Finally, hemispheric means have been calculated by averaging $d$ over all grid boxes in the respective hemisphere, weighted with the grid box surface area and mean latent heat flux. The weighting with latent heat flux (or, equivalently, surface evaporation) is necessary to compare with the precipitation-weighted GNIP data (see below) and to close the $d$ budget of the atmospheric water cycle.

In order to evaluate our model, measurements of $d$ in monthly precipitation from the Global Network of Isotopes in Precipitation (GNIP) (IAEA, 2006; Araguás-Araguás et al., 2000) have been employed. All stations have been considered for which at least 36 months of data of $\delta \mathrm{D}, \delta^{18} \mathrm{O}$ and precipitation amount were available during the period 1960-2009. Precipitation-weighted climatological means of $d$ for every calendar month and season have been calculated at each station with at least three observations from the respective month, or nine from the respective season. To obtain hemispheric means of $d$ in precipitation, station data have first been averaged over $10^{\circ} \times 10^{\circ}$ grid boxes, then the grid box mean values have been averaged zonally and meridionally, weighted by the grid box sizes and mean precipitation amounts. The hemispheric means obtained in this way are in good agreement with the results of Araguás-Araguás et al. (2000), who used a similar dataset. To first order, one can assume that moisture exchange between the hemispheres is negligible, because mean moisture fluxes in most tropical regions and seasons have a much larger zonal than meridional component (e.g. Trenberth, 1999). Therefore, the hemispheric means of $d$ in precipitation and ocean evaporation, according to the global closure assumption (see Sect. 1), should be equal when averaged over sufficiently long time periods. However, the tropical monsoon systems, in particular the Indian summer monsoon, do in fact lead to a net inter-hemispheric moisture transport. This is a potential error source in the comparison of hemispherically averaged model results and observations.

\section{Results and discussion}

\subsection{Deuterium excess and relative humidity}

Figure $1 \mathrm{~b}$ shows the predicted mean seasonal cycle of $d$ in ocean evaporation from our statistical model, averaged over the Northern Hemisphere $(\mathrm{NH})$ and Southern Hemisphere $(\mathrm{SH})$. Both curves have a maximum in winter, and the amplitude of the seasonal cycle is larger in the NH than in the SH. The model results are in very good quantitative agreement with the hemispherically averaged GNIP data. The close correspondence with respect to phase, amplitude, and absolute values is striking given that our model is fully independent from the precipitation data and uses flux-weighted $\mathrm{RH}$ as its only input parameter. In the $\mathrm{NH}$, the seasonal cycle of $d$ in precipitation has a slightly smaller amplitude compared to the statistical model. This is likely caused by the fact that part of the precipitation originates from recycling of continental moisture and that the residence time of this moisture over the continents is often larger than 1 month (Numaguti, 1999), which induces a smoothing of the seasonal cycle in continental precipitation. In the $\mathrm{SH}$, the model has a positive bias of 1-2\%o compared to the precipitation data. This may be partly due to the sparse spatial coverage of GNIP stations; there are no data, e.g. over large parts of the Southern Ocean where evaporation $d$ is relatively high (see below). Other possible reasons are errors in the measurements of $d$ in precipitation or in the formulation of the linear model. A small positive bias is also found in the global and annual mean $d$ values: The observed global mean $d$ in precipitation is $10.0 \%$, while the predicted global mean $d$ in ocean evaporation is $10.8 \%$. Nevertheless, taking potential uncertainties of the statistical model, global averaging and the $d$ measurement in precipitation into account, this bias of less than $1 \%$ is remarkably small. When using monthly instead of sixhourly RH and LHF data as input for the statistical model, the predicted seasonal cycles of evaporation $d$ have a comparable amplitude, but the values are lower $(9.3 \%$ instead of $10.8 \%$ in the global mean). These lower values are due to the episodic nature of strong oceanic evaporation (evaporation is 


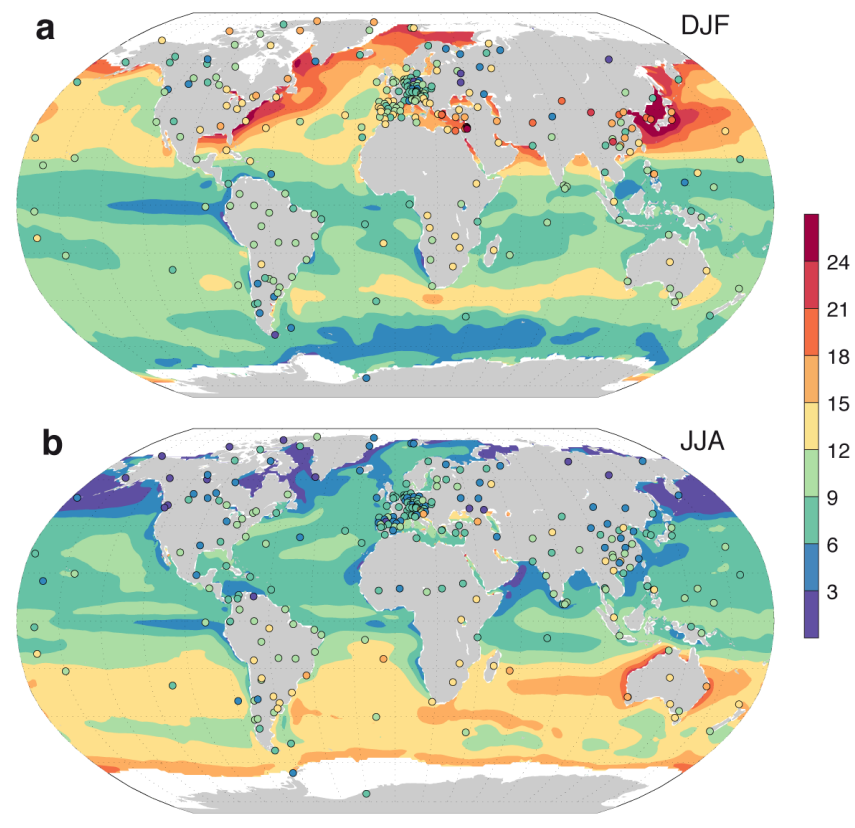

Fig. 2. Spatial distribution of predicted evaporation $d$ (shading) and observed $d$ in precipitation (circles). Colour shading shows seasonal mean $d$ of ocean surface evaporation, as obtained from the regression model and RH from atmospheric reanalyses, for the seasons December-February (a) and June-August (b). Regions with sea ice in the seasonal mean are masked in white. The coloured circles show seasonal mean $d$ of precipitation at GNIP stations. Note that evaporation and precipitation $d$ are not expected to directly correspond, since precipitation $d$ at each station is influenced by regionally varying moisture sources.

particularly large in periods with low $\mathrm{RH}$, corresponding to high $d$ ), which is neglected using monthly data. In spite of this systematic underestimation, the match with the precipitation observation is still reasonable, also because the underestimation is partly compensated by the positive bias of the statistical model.

We now focus our attention on the seasonally averaged spatial patterns of $d$ in moisture evaporating from the ocean that are obtained from our model (Fig. 2, shading), before comparing to the GNIP station data. These patterns also reflect the strong seasonality in the $\mathrm{NH}$, and a weaker, opposite signal in the SH. The spatial patterns are strongly related to evaporation-weighted RH over the ocean (Fig. 3a, b). During NH winter, high values of $d$ are predicted downstream (i.e. to the east) of North America and eastern Asia (Fig. 2a, red colours), associated with intense oceanic evaporation (cf. Fig. 3e, f) into dry continental air masses advected over the adjacent oceans with the mean westerly circulation. The large humidity gradients over the sea surface lead to strong non-equilibrium fractionation resulting in high $d$ values. A further maximum of $d$ is predicted in the region of the Barents Sea. In the SH winter, maxima of $d$ are found near the sea ice edge, and at the coast of Australia (Fig. 2b). The weaker seasonality of $d$ in the SH is likely due to the absence of large midlatitude continental areas. Hence, while induced by oceanic RH in both hemispheres, $d$ in precipitation appears to be influenced by the differing land-sea distribution.

Comparison of predicted $d$ in evaporation with GNIP precipitation measurements is complicated by the fact that the precipitation at each station originates from various oceanic moisture sources. For this reason, no simple direct correspondence between evaporation and precipitation $d$ can be expected at many stations. Nevertheless, several large-scale spatial features of predicted $d$ in ocean evaporation are also reflected in the seasonally averaged precipitation data from GNIP stations (circles in Fig. 2). The zonal gradient of evaporation $d$ across the main ocean basins in the $\mathrm{NH}$ during winter is mirrored by higher precipitation $d$ in the eastern than in the western parts of the North American and the Eurasian continents (Fig. 2a). Very high precipitation $d$ is observed at eastern Mediterranean stations in $\mathrm{NH}$ winter, reflecting the high $d$ in water evaporating from the surrounding seas (Gat et al., 2003). In the SH, Pacific island stations show lower precipitation $d$ than predicted for evaporation, partly causing the offset between measurements and model results seen in Fig. 1. To some extent these differences may be due to interannual variability, since several stations only cover a limited number of years.

Despite the similarities between predicted evaporation and measured precipitation $d$, it is important to keep in mind that at a single location precipitation $d$ is also affected by variations in the moisture source regions, and by secondary effects such as differences in the isotopic composition of the ocean source as well as isotopic fractionation during the progressive cooling of an air mass, during ice cloud formation and during the evaporation of raindrops and soil water (Jouzel and Merlivat, 1984; Jouzel et al., 2007). Such secondary effects are particularly important at high latitudes, where most of the precipitation falls as snow. Due to mass conservation, the secondary effects cancel out if long-term hemispheric averages are considered, as demonstrated by the good correspondence between predicted $d$ in ocean evaporation and GNIP precipitation data (Fig. 1b). Nevertheless, they may cause discrepancies between measured $d$ in precipitation and the predicted moisture source $d$ at certain stations, like in Iceland and southern Greenland (see again Fig. 2). Due to the difficult measurement conditions at some of these sites one should not exclude the potential for biases or errors in the measurements, which may particularly affect the relatively sensitive parameter $d$. The primary influence on local-scale variability of precipitation $d$ is the seasonal and spatial variation of moisture sources, which can be large (Sodemann et al., 2008b; Sodemann and Zubler, 2010). Sophisticated methods for diagnosing moisture source regions hence have to be applied to fully explain $d$ in precipitation at individual stations in terms of the moisture source RH (Sodemann et al., 2008a; Pfahl and Wernli, 2008, 2009), in particular for continental stations, as is the case for a substantial part of the 

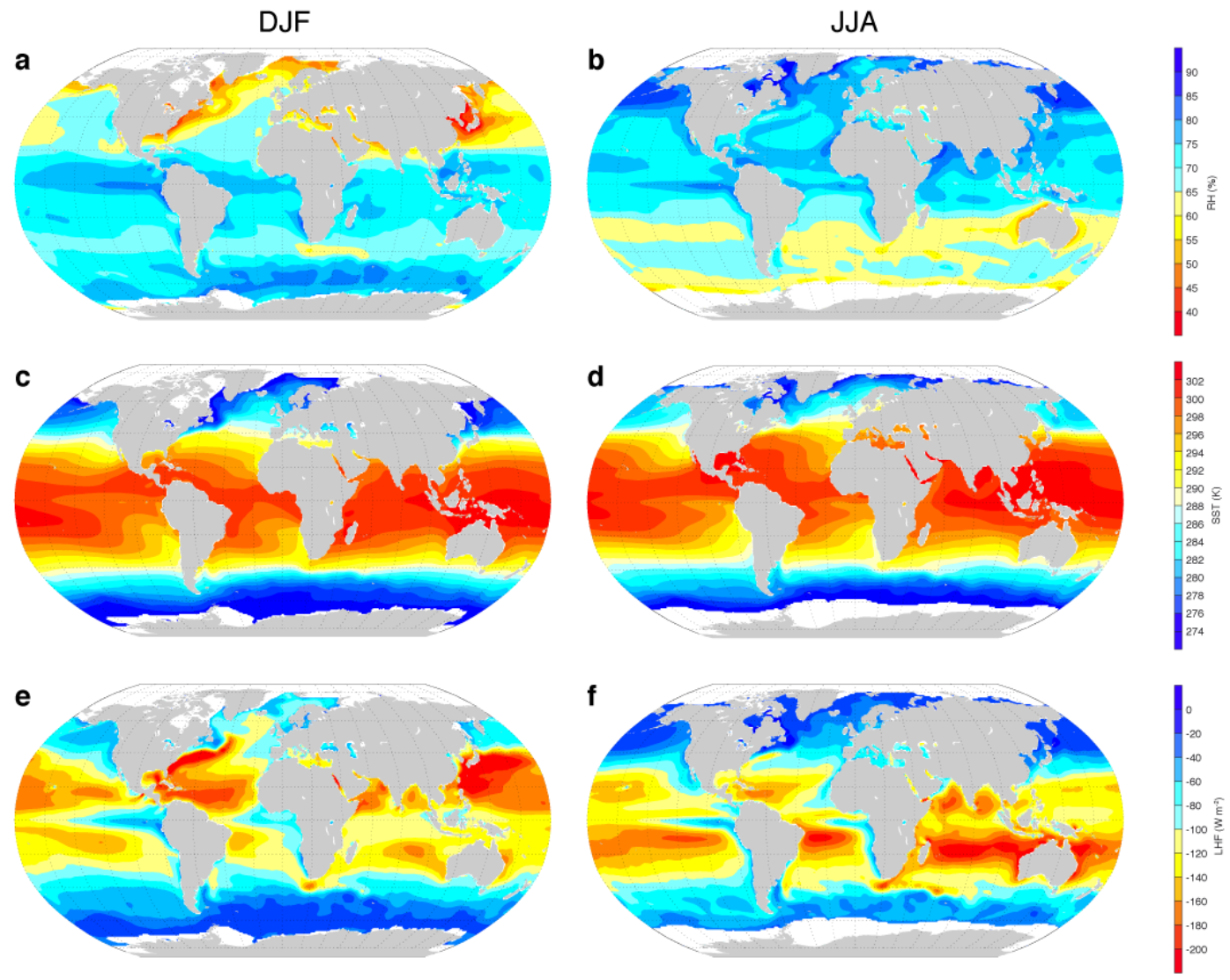

Fig. 3. Seasonal means of relative humidity over the ocean for DJF (December-January-February) (a) and JJA (June-July-August) (b), sea surface temperature for DJF (c) and JJA (d), as well as surface LHF for DJF (e) and JJA (f). The means of both RH and SST are weighted averages, using the local LHF as a weight. Regions with sea ice in the seasonal mean are masked in white.

GNIP network. In turn, the relationship between $d$ and RH opens the possibility to constrain such model-based moisture source diagnostics. In addition, changes in moisture transport induced by climate change, which can lead to variations in regional-scale moisture budgets, may be quantifiable through their $d$ fingerprint.

In summary, this comparison shows that there is a close correspondence between hemispherically averaged seasonal cycles of predicted $d$ in evaporation and measurements of $d$ in precipitation. Near-surface relative humidity is used as sole predictor of evaporation $d$, and thus the seasonal cycles of $d$ and RH are linearly related (Fig. 4, black and red lines). In turn, there is a close in-phase relationship between the seasonal cycles of $\mathrm{RH}$ and the average temperature above land areas (Fig. 4, green lines), which reflects the surface radiation balance. With regard to the spatial patterns of $d$ in ocean evaporation and precipitation, there is some correspondence of large-scale features, but there are also differences on local scales due to variations in moisture source regions and processes not taken into account in our simple model, like the formation of ice clouds.

\subsection{Potential influence of SST}

The conspicuous agreement of our model results with GNIP measurement data shows that the linear relationship between $d$ and moisture source $\mathrm{RH}$, which has been derived from observations on (sub-)daily timescales and captures a fundamental isotopic process during ocean evaporation, also dominates seasonal variations of $d$ in precipitation on a hemispheric scale. In contrast, there is much less resemblance between $d$ and SST, both spatially and temporally: the spatial distribution of SST (Fig. 3c, d) has a much stronger meridional gradient and less zonal variability compared to observed $d$ in precipitation. A phase shift between the hemispherically averaged seasonal cycles of the two variables exists (Fig. 4, black and blue lines). The positive correlation of $d$ and SST usually assumed in palaeoclimatological reconstructions (Johnsen et al., 1989; Vimeux et al., 1999; Masson-Delmotte et al., 2005, see also Eq. 3) is at odds with the timing of the respective seasonal cycles (note the reversed scale for $d$ in Fig. 4). Also on a daily timescale a much weaker correlation and much less resemblance to a linear relation is found in the measurement data that form the basis 


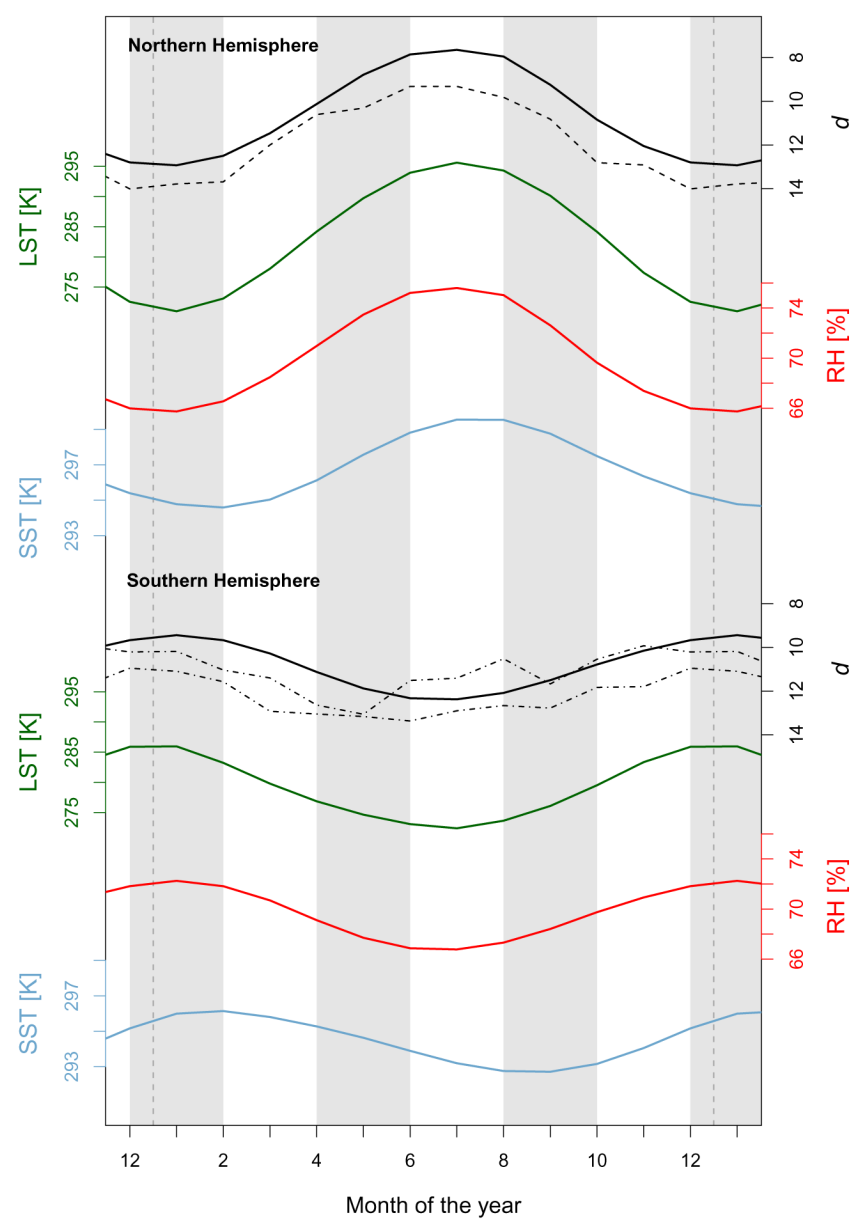

Fig. 4. Hemispheric mean seasonal cycle of predicted $d$ in comparison with other variables. The black lines show the averaged $d$ of ocean evaporation as predicted by the regression model. Green lines show averages of land surface temperature (LST). Mean RH over the ocean and SST, both weighted with the surface latent heat flux, are shown by red and blue lines, respectively. Seasonally resolved $d$ from a shallow ice core from the NEEM site, Greenland, covering a $41 \mathrm{yr}$ period (Steen-Larsen et al., 2011) is shown as a dashed line. The dashed-dotted lines show the seasonal cycle from two cores from Law Dome, Antarctica, covering $12 \mathrm{yr}$ (Delmotte et al., 2000) shifted by $8 \%$.

of this study between $d$ and SST (Fig. 5) compared to $d$ and RH (cf. Fig. 1a).

Nevertheless, all these findings are based on the analysis of present-day climate, and it is not guaranteed that the relation between $d$ and RH also dominates long-term palaeoclimatic $d$ variations. Many previous studies have interpreted such $d$ variations in terms of moisture source temperature (see Sect. 1). They have presented different arguments for this interpretation, which we would like to discuss in the following. It is not the main purpose of this paragraph to provide new evidence for the relevance of $\mathrm{RH}$ also on palaeoclimatic timescales, but rather to critically revisit existing arguments

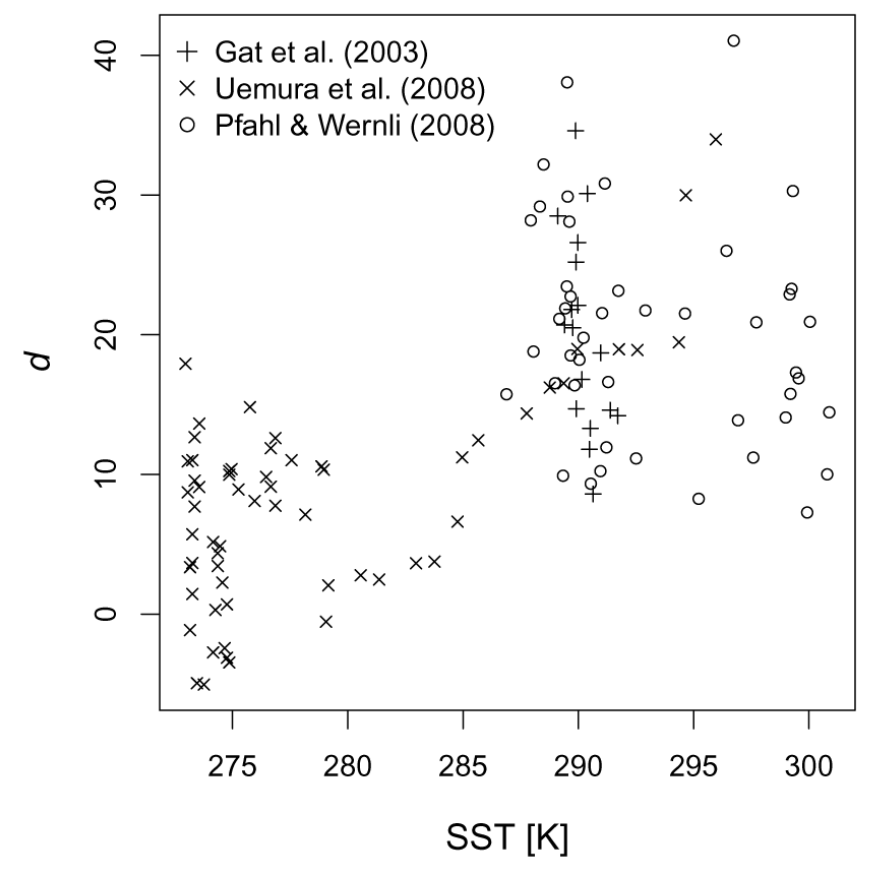

Fig. 5. Scatter plot of water vapour $d$ from several published data sets (Gat et al., 2003; Uemura et al., 2008; Pfahl and Wernli, 2008) against SST at the oceanic moisture source.

for the association of long-term $d$ changes with source temperature variations.

- Vimeux et al. (1999) argued that changes of RH over the Southern Ocean between glacial and present-day climate simulated by GCMs are typically small. In addition, global-scale changes of RH are constrained to small values by the surface energy budget (Schneider et al., 2010). However, even if mean RH stays constant, the $d-\mathrm{RH}$ relationship may yet be associated with $d$ variations in proxy archives. For example, if the moisture sources of an ice core shift from regions with high to regions with low RH (e.g. from the eastern to the western North Atlantic), this may cause huge changes in the resulting precipitation $d$. Similarly, shifts in precipitation seasonality (Krinner et al., 1997; Werner et al., 2000) may lead to large variations in annual mean $d$ due to the strong seasonal cycle of $d$ at the evaporation source. In addition, also if global mean changes in RH are small, local variations can occur, e.g. due to changes in sea ice cover, land-sea temperature contrast or storm tracks.

- Uemura et al. (2008) found a positive correlation between $d$ and SST in measurements along a ship cruise from South Africa to the sea ice edge and back towards Australia. However, the spatial patterns of RH, SST and $d$ shown in Figs. 3a, c and 2a suggest that this may be explained by cross-correlation with RH (positive gradient of RH and negative gradient of SST along 
parts of the ship track) and thus does not represent an independent confirmation of the effect of SST on $d$. Other studies based on measurement data (Gat et al., 2003; Pfahl and Wernli, 2008) even found a negative relationship between $d$ and SST on the daily timescale (cf. Fig. 5).

- The $d-\mathrm{RH}$ relationship would translate into a positive correlation between $d$ and SST (as widely assumed in the interpretation of ice cores) if variations of SST and RH were always anti-correlated. However, there is no such systematic anti-correlation of SST and $\mathrm{RH}$ in observations. On short, daily timescales, RH and near-surface air temperature time series are correlated in the extratropics and anti-correlated in the tropics (Pfahl and Niedermann, 2011). If SST is considered instead of near-surface air temperature, these (anti-)correlations are generally much weaker, since the magnitude of daily SST variations is smaller than for air temperature (not shown). Also on longer, interannual timescales there is no systematic covariance between near-surface RH and temperature time series (Fig. 18b of Dai, 2006). Figure 6 shows scatter plots of $d$ from our empirical model plotted against SST at the respective grid points. Since the model is linear, the same patterns are obtained if $\mathrm{RH}$ is used instead of $d$. No systematic relationship between $d$ (or $\mathrm{RH}$ ) and SST can be found in these plots, indicating that the first-order relationship between $d$ and $\mathrm{RH}$, which has been used to construct the model, does not translate into a simple correlation of $d$ and SST. All together, this demonstrates the complexity of the relation between RH and SST. We are not aware of (and do not foresee) a physical argument which could evoke a direct anti-correlation between long-term changes of the two variables.

- Johnsen et al. (1989) used the phase shift between the seasonal cycles of $d$ and $\delta^{18} \mathrm{O}$ in Greenland ice as an indicator of the effects of SST on $d$. However, the seasonal $d$ cycles from shallow ice cores form the NEEM (North Greenland Eemian Ice Drilling) site, Greenland (Steen-Larsen et al., 2011) and Law Dome, Antarctica (Delmotte et al., 2000), do not correspond with the seasonal cycle of SST (Fig. 4, dashed and blue lines). On the contrary, there is a good agreement between the NEEM data and our hemispheric-mean model predictions (black solid lines). At Law Dome, the signal is more variable, pointing to a larger influence of local factors. Note that such a comparison with ice core data is difficult in general due to diffusion in the ice and dating uncertainties. Ultimately, it would be preferable to compare to precipitation observations sampled directly at ice core sites (e.g. Fujita and Abe, 2006). Nonetheless, taking the $d$ seasonality in published ice core data at face value, they do not argue strongly towards SST influences, and are not inconsistent with $\mathrm{RH}$ being the primary factor.

- Recent climate model studies suggest that long-term $d$ variations throughout the Holocene may be related to SST changes to some degree (Lewis et al., 2013). However, different models seem not to show consistent results (cf. Risi et al., 2013), and such a conclusion may be affected by model errors, as isotope-enabled GCMs still have difficulties to properly represent the spatial and temporal variability of $d$ (Yoshimura et al., 2008; Risi et al., 2010; Jouzel et al., 2007). Recent improvements in the ECHAM5-wiso (water isotope) model are partly due to tuning of the supersaturation function used in the parameterisation of ice clouds (Werner et al., 2011). The large sensitivity of modelled $d$ to this tuning (see again Risi et al., 2013) may lead to additional problems: a supersaturation function tuned for present-day climate does not necessarily represent, e.g. last glacial maximum conditions correctly. Future studies on this issue may make use of a prognostic representation of supersaturation in ice clouds that does not require such tuning (Pfahl et al., 2012). In general, models should be thoroughly validated to properly represent the $\mathrm{RH}-d$ relationship that controls present-day seasonal $d$ variations. Being available with high temporal and spatial resolution, $d$ from our model can be used as a benchmark for such simulations.

The above discussion leads us to conclude that there is not sufficient evidence that would justify to neglect the influence of RH on palaeoclimatic $d$ variations. If this holds, either the interpretation of $d$ variations in palaeorecords will have to be adapted to reflect climatic influences on RH during evaporation, or new arguments for an interpretation in terms of moisture source SST should be provided based on future research.

\section{Conclusions}

In this paper, the relationship between $d$ and moisture source RH under present-day climate conditions has been studied with the help of a simple, linear empirical model. We have shown that the $d-\mathrm{RH}$ relation observed on daily timescales also explains the seasonal cycle of hemispherically averaged $d$ in precipitation and several large-scale features of its spatial distribution. Our statistical model is currently based on a relatively small set of in situ measurements of $d$ in water vapour, and uncertainties of the model as well as the applicability of vapour data for assessing evaporation $d$ should be reexamined with additional observations in future research. With respect to the interpretation of $d$ proxy records, the relationship between $d$ and RH can serve as a first-order interpretation guide. It suggests that $d$ variations from proxy records could be used to reconstruct $\mathrm{RH}$ during evaporation, 

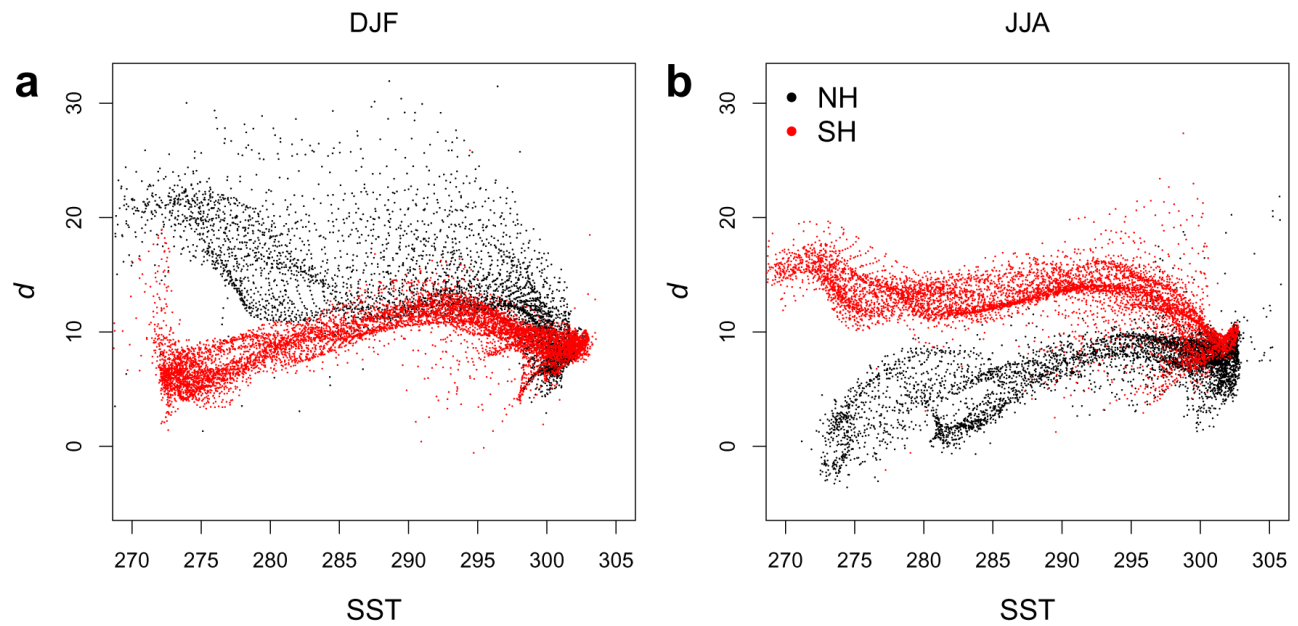

Fig. 6. Seasonal means of $d$ as obtained from our model plotted against seasonal mean SST from the corresponding ERA-Interim grid boxes for (a) DJF and (b) JJA. For clarity, only every third point is shown.

which is strongly affected by variations in atmospheric circulation and the corresponding changes of moisture source locations. This first-order interpretation is in analogy to the classical temperature effect: spatial and temporal correlations between isotope ratios $\left(\delta \mathrm{D}\right.$ and $\left.\delta^{18} \mathrm{O}\right)$ and temperature have been observed under present-day climate conditions (Dansgaard, 1964) and were subsequently used to link isotope signals from proxy archives to past temperature variations (e.g. Dansgaard et al., 1993). Nevertheless, for a detailed and quantitative analysis of isotope proxy data from individual locations, additional processes have to be taken into account. Regarding the classical temperature effect, e.g. variations in precipitation seasonality and moisture source temperature can influence the relationship between isotope ratios and temperature at the proxy location (Krinner et al., 1997; Werner et al., 2000; Masson-Delmotte et al., 2005). Precipitation seasonality can also impact $d$ because of the large seasonal variability of RH over the ocean. In addition, the $d-$ $\mathrm{RH}$ relation may be affected by second-order parameters like wind speed and SST as well as non-equilibrium fractionation processes during soil evaporation, the re-evaporation of raindrops and, most importantly for ice core locations, the formation of ice clouds (see again Jouzel and Merlivat, 1984; Jouzel et al., 2007). Assessing the relationship between $d$ and moisture source RH is complicated due to its non-local character. In order to fully explore the linkage between $d$ proxy records and moisture source conditions, sophisticated methods thus have to be applied, e.g. using tracer simulations with GCMs (Lewis et al., 2013) or Lagrangian techniques (Sodemann et al., 2008a).

Reinterpreting ice core $d$ as moisture source RH could resolve several complications that have arisen from its previous interpretation as moisture source SST. For example, rapid changes of $d$ in the NGRIP (North Greenland Ice Core Project) ice core of 2-3\%o within 1-3 yr have been used by
Steffensen et al. (2008) to reconstruct moisture source temperature changes of $2-4 \mathrm{~K}$ (even though the authors left room for other possible interpretations). Following their SST interpretation, during the transition from the Younger Dryas (YD) to the Holocene $d$ would decrease, which would imply cooler moisture source temperatures for Greenland in a warmer climate, at least for the beginning of the Holocene (MassonDelmotte et al., 2005; Steffensen et al., 2008). This counterintuitive finding was explained by the temporary exposure of cooler ocean areas after the retreat of the sea ice, and fast reorganisations of the atmospheric circulation. Interpreting $d$ as driven by RH eliminates the need to involve climate components with inter-annual memory, such as SST and sea ice cover. An alternative explanation of the $d$ decrease from the YD to the Holocene would involve reduced land-sea temperature contrasts, relatively more summer precipitation, eastward shifts of the moisture sources in the North Atlantic basin due to a weakened storm track, or a combination of these factors. A combined interpretation of all available data, including GCM studies of past climate states, and the acquisition of new high-resolution isotopic measurements will be crucial to disentangle the interaction between these processes.

Acknowledgements. MeteoSwiss and ECMWF are acknowledged for giving access to ERA-Interim reanalyses, and the IAEA for providing the GNIP data. We are grateful to Nele Meckler and Heini Wernli (ETH Zurich) as well as Valérie Masson-Delmotte (LSCE, IPSL) for helpful comments on an earlier version of the manuscript. Comments from Martin Werner, Jesper Sjolte and an anonymous reviewer helped us to further improve the manuscript.

Edited by: E. Zorita 


\section{References}

Angert, A., Lee, J.-E., and Yakir, D.: Seasonal variations in the isotopic composition of near surface water vapor in the EasternMediterranean, Tellus B, 60, 674-684, doi:10.1111/j.16000889.2008.00357.x, 2008.

Araguás-Araguás, L., Froehlich, K., and Rozanski, K.: Deuterium and oxygen-18 isotope composition of precipitation and atmospheric moisture, Hydrol. Process., 14, 1341-1355, 2000.

Craig, H. and Gordon, L. I.: Deuterium and oxygen 18 variations in the ocean and the marine atmosphere, in: Stable Isotopes in Oceanographic Studies and Paleotemperatures, edited by: Tongiorgi, E., Lab. Geol. Nucl., Pisa, Italy, 9-130, 1965.

Dai, A.: Recent climatology, variability, and trends in global surface humidity, J. Climate, 19, 3589-3606, 2006.

Dansgaard, W.: Stable isotopes in precipitation, Tellus B, 16, 436468, 1964.

Dansgaard, W., Johnsen, S. J., Clausen, H. B., Dahl-Jensen, D., Gundestrup, N. S., Hammer, C. U., Hvidberg, C. S., Steffensen, J. P., Sveinbjörnsdottir, A. E., Jouzel, J., and Bond, G.: Evidence for general instability of past climate from a $250-\mathrm{kyr}$ ice-core record, Nature, 364, 218-220, 1993.

Dee, D. P., Uppala, S. M., Simmons, A. J., Berrisford, P., Poli, P., Kobayashi, S., Andrae, U., Balmaseda, M. A., Balsamo, G., Bauer, P., Bechtold, P., Beljaars, A. C. M., van de Berg, L., Bidlot, J., Bormann, N., Delsol, C., Dragani, R., Fuentes, M., Geer, A. J., Haimberger, L., Healy, S. B., Hersbach, H., Holm, E. V., Isaksen, L., Kallberg, P., Koehler, M., Matricardi, M., McNally, A. P., Monge-Sanz, B. M., Morcrette, J.-J., Park, B.-K., Peubey, C., de Rosnay, P., Tavolato, C., Thepaut, J.-N., and Vitart, F.: The ERA-Interim reanalysis: configuration and performance of the data assimilation system, Q. J. Roy. Meteorol. Soc., 137, 553597, doi:10.1002/qj.828, 2011.

Delmotte, M., Masson, V., Jouzel, J., and Morgan, V. I.: A seasonal deuterium excess signal at Law Dome, coastal eastern Antarctica: a southern ocean signature, J. Geophys. Res., 105, 71877197, 2000.

Fujita, K. and Abe, O.: Stable isotopes in daily precipitation at Dome Fuji, East Antarctica, Geophys. Res. Lett., 33, L18503, doi:10.1029/2006GL026936, 2006.

Gat, J. R.: Oxygen and hydrogen isotopes in the hydrological cycle, Annu. Rev. Earth Pl. Sc., 24, 225-262, 1996.

Gat, J. R., Klein, B., Kushnir, Y., Roether, W., Wernli, H., Yam, R., and Shemesh, A.: Isotope composition of air moisture over the Mediterranean Sea: an index of the air-sea interaction pattern, Tellus B, 55, 953-965, 2003.

IAEA: Global Network of Isotopes in Precipitation, The GNIP Database, available at: http://www.iaea.org/water (last access: 23 May 2012), 2006.

Johnsen, S. J., Dansgaard, W., and White, J. W. C.: The origin of Arctic precipitation under present and glacial conditions, Tellus B, 41, 452-468, 1989.

Jouzel, J. and Koster, R. D.: A reconsideration of the initial conditions used for stable water isotope models, J. Geophys. Res., 101, 22933-22938, 1996.

Jouzel, J. and Merlivat, L.: Deuterium and oxygen 18 in precipitation: modeling of the isotope effects during snow formation, $\mathrm{J}$. Geophys. Res., 89, 11749-11757, 1984.

Jouzel, J., Merlivat, L., and Lorius, C.: Deuterium excess in an East Antarctic ice core suggests higher relative humidity at the oceanic surface during the last glacial maximum, Nature, 299, 688-691, 1982.

Jouzel, J., Stievenard, M., Johnsen, S. J., Landais, A., MassonDelmotte, V., Sveinbjörnsdottir, A., Vimeux, F., von Grafenstein, U., and White, J. W. C.: The GRIP deuterium-excess record, Quaternary Sci. Rev., 26, 1-17, 2007.

Krinner, G., Genthon, C., and Jouzel, J.: GCM analysis of local inflluences on ice core $\delta$ signals, J. Climate, 24, 2825-2828, doi:10.1029/97GL52891, 1997.

Kurita, N.: Origin of Arctic vapor during the ice-growth season, Geophys. Res. Lett., 38, L02709, doi:10.1029/2010GL046064, 2011.

Lewis, S. C., LeGrande, A. N., Kelley, M., and Schmidt, G. A.: Modeling insights into deuterium excess as an indicator of water vapor source conditions, J. Geophys. Res., 118, 243-262, doi:10.1029/2012JD017804, 2013.

Luz, B., Barkan, E., Yam, R., and Shemesh, A.: Fractionation of oxygen and hydrogen isotopes in evaporating water, Geochim. Cosmochim. Ac., 73, 6697-6703, doi:10.1016/j.gca.2009.08.008, 2009.

Masson-Delmotte, V., Jouzel, J., Landais, A., Stievenard, M., Johnsen, S. J., White, J. W. C., Werner, M., Sveinbjörnsdottir, A., and Fuhrer, K.: GRIP deuterium excess reveals rapid and orbitalscale changes in Greenland moisture origin, Science, 309, 118 121, 2005.

Meckler, A. N., Clarkson, M. O., Cobb, K. M., Sodemann, H., and Adkins, J. F.: Interglacial hydroclimate in the tropical west Pacific through the late Pleistocene, Science, 336, 1301-1304, doi:10.1126/science.1218340, 2012.

Merlivat, L. and Jouzel, J.: Global climatic interpretation of the deuterium-oxygen 18 relationship for precipitation, J. Geophys. Res., 84, 5029-5033, 1979.

Numaguti, A.: Origin and recycling processes of precipitating water over the Eurasian continent: experiments using an atmospheric general circulation model, J. Geophys. Res., 104, 1957-1972, 1999.

Pfahl, S. and Niedermann, N.: Daily co-variations in near-surface relative humidity and temperature over the ocean, J. Geophys. Res., 116, D19104, doi:10.1029/2011JD015792, 2011.

Pfahl, S. and Wernli, H.: Air parcel trajectory analysis of stable isotopes in water vapor in the eastern Mediterranean, J. Geophys. Res., 113, D20104, doi:10.1029/2008JD009839, 2008.

Pfahl, S. and Wernli, H.: Lagrangian simulations of stable isotopes in water vapor - an evaluation of non-equilibrium fractionation in the Craig-Gordon model, J. Geophys. Res., 114, D20108, doi:10.1029/2009JD012054, 2009.

Pfahl, S., Wernli, H., and Yoshimura, K.: The isotopic composition of precipitation from a winter storm - a case study with the limited-area model $\mathrm{COSMO}_{\text {iso }}$, Atmos. Chem. Phys., 12, 16291648, doi:10.5194/acp-12-1629-2012, 2012.

Risi, C., Bony, S., Vimeux, F., and Jouzel, J.: Water-stable isotopes in the LMDZ4 general circultaion model: model evaluation for present-day and past climates and applications to climatic interpretations of tropical isotopic records, J. Geophys. Res., 115, D12118, doi:10.1029/2009JD013255, 2010.

Risi, C., Landais, A., Winkler, R., and Vimeux, F.: Can we determine what controls the spatio-temporal distribution of $\mathrm{d}$ excess and ${ }^{17} \mathrm{O}$-excess in precipitation using the LMDZ general 
circulation model?, Clim. Past, 9, 2173-2193, doi:10.5194/cp-92173-2013, 2013.

Schneider, T., O'Gorman, P. A., and Levine, X. J.: Water vapor and the dynamics of climate changes, Rev. Geophys., 48, RG3001, doi:10.1029/2009RG000302, 2010.

Simmons, A. J., Willett, K. M., Jones, P. D., Thorne, P. W., and Dee, D. P.: Low-frequency variations in surface atmospheric humidity, temperature, and precipitation: Inferences from reanalysis and monthly gridded observational data sets, J. Geophys. Res., 115, D01110, doi:10.1029/2009JD012442, 2010.

Sodemann, H. and Zubler, E.: Seasonal and inter-annual variability of the moisture sources for Alpine precipitation during 19952002, Int. J. Climatol., 30, 947-961, doi:10.1002/joc.1932, 2010.

Sodemann, H., Masson-Delmotte, V., Schwierz, C., Vinther, B., and Wernli, H.: Inter-annual variability of Greenland winter precipitation sources. Part II: Effects of North Atlantic oscillation variability on stable isotopes in precipitation, J. Geophys. Res., 113, D12111, doi:10.1029/2007JD009416, 2008a.

Sodemann, H., Schwierz, C., and Wernli, H.: Inter-annual variability of Greenland winter precipitation sources. Part I: Lagrangian moisture diagnostic and North Atlantic oscillation influence, J. Geophys. Res., 113, D03107, doi:10.1029/2007JD008503, 2008b.

Steen-Larsen, H. C., Masson-Delmotte, V., Sjolte, J., Johnsen, S. J., Vinther, B. M., Breon, F.-M., Clausen, H. B., Dahl-Jensen, D., Falourd, S., Fettweis, X., Gallee, H., Jouzel, J., Kageyama, M., Lerche, H., Minster, B., Picard, G., Punge, H. J., Risi, C., Salas, D., Schwander, J., Steffen, K., Sveinbjoernsdottir, A. E., Svensson, A., and White, J.: Understanding the climatic signal in the water stable isotope records from the NEEM shallow firn/ice cores in northwest Greenland, J. Geophys. Res., 116, D06108, doi:10.1029/2010JD014311, 2011.

Steffensen, J. P., Andersen, K. K., Bigler, M., Clausen, H. B., DahlJensen, D., Fischer, H., Goto-Azuma, K., Hansson, M., Johnsen, S. J., Jouzel, J., Masson-Delmotte, V., Popp, T., Rasmussen, S. O., Roethlisberger, R., Ruth, U., Stauffer, B., Siggaard-Andersen, M.-L., Sveinbjornsdottir, A. E., Svensson, A., and White, J. W. C.: High-resolution Greenland Ice Core data show abrupt climate change happens in few years, Science, 321, 680-684, doi:10.1126/science.1157707, 2008.
Stenni, B., Masson-Delmotte, V., Johnsen, S., Jouzel, J., Longinelli, A., Monnin, E., Röthlisberger, R., and Selmo, E.: An oceanic cold reversal during the last deglaciation, Science, 293, 2074-2077, 2001.

Trenberth, K. E.: Atmospheric moisture recycling: role of advection and local evaporation, J. Climate, 12, 1368-1381, 1999.

Uemura, R., Matsui, Y., Yoshimura, K., Motoyama, H., and Yoshida, N.: Evidence of deuterium excess in water vapor as an indicator of ocean surface conditions, J. Geophys. Res., 113, D19114, doi:10.1029/2008JD010209, 2008.

Uemura, R., Masson-Delmotte, V., Jouzel, J., Landais, A., Motoyama, H., and Stenni, B.: Ranges of moisture-source temperature estimated from Antarctic ice cores stable isotope records over glacial-interglacial cycles, Clim. Past, 8, 11091125, doi:10.5194/cp-8-1109-2012, 2012.

Vimeux, F., Masson, V., Jouzel, J., Stievenard, M., and Petit, J. R.: Glacial-interglacial changes in ocean surface conditions in the Southern Hemisphere, Nature, 398, 410-413, 1999.

Werner, M., Mikolajewicz, U., Heimann, M., and Hoffmann, G.: Borehole versus isotope temperatures on Greenland: seasonality does matter, Geophys. Res. Lett., 27, 723-726, 2000.

Werner, M., Langebroek, P. M., Carlsen, T., Herold, M., and Lohmann, G.: Stable water isotopes in the ECHAM5 general circulation model: toward high-resolution isotope modeling on a global scale, J. Geophys. Res., 116, D15109, doi:10.1029/2011JD015681, 2011.

Yoshimura, K., Kanamitsu, M., Noone, D., and Oki, T.: Historical isotope simulation using reanalysis atmospheric data, J. Geophys. Res., 113, D19108, doi:10.1029/2008JD010074, 2008. 